\title{
ISOLATION OF TUBERCLE BACILLI FROM SPUTUM AND DETERMINATION OF THEIR TYPE. ${ }^{1}$
}

\author{
By Chung Yik Wang, M.B., B.Sc., Carnegie Research Scholar; \\ formerly McCunn Research Scholar.
}

From the Research Laboratory of the Royal College of Plysicians, Edinburgh.

(Plate V.)

WHILE engaging in the study of other aspects of tuberculosis, I had opportunities of determining the type of tubercle bacilli isolated from unselected specimens of sputum which had been sent by physicians in ordinary course to the Reporting Department of the Laboratory for examination, and in which tubercle bacilli were detected by the usual microscopic methods.

The sputum from thirty-six cases was studied, and in twenty-nine instances cultures were isolated and tested as to their virulence; in the remaining seven cases a complete investigation was not possible, as in two instances the cultures isolated were subsequently found to be dead; in one instance both guinea-pigs inoculated for the isolation of tubercle bacilli died prematurely; and in the other four instances, where the antiformin method was employed, no growth was obtained.

\section{Method of obtaining Primary Cultures.}

Two methods have been adopted in obtaining primary cultures, " indirect" and "direct."

Indirect method.-By this method cultures were obtained from fifteen out of eighteen cases. The sputum was inoculated intraperitoneally into two or more guinea-pigs in each case, and cultures were obtained from those which did not die prematurely. If very thick in consistence, the sputum was diluted with normal physiological saline solution before being injected.

Direct method.-Cultures were isolated from fourteen out of eighteen samples of sputum. The sputum, when brought to the Laboratory, was put into a sterile bottle, and, depending on its thickness, such amount of saline solution was added that the resulting

2 Receired June 19, 1916. 
mixture was of a thin mucoid consistence. To this, antiformin of such an amount was added that it would constitute 20 per cent. to 25 per cent. in the whole mixture. The treated sputum was then well mixed, and, after being laid aside for an hour at $37^{\circ}$.C., the mixture was centrifuged - this time, at the temperature stated, was found sufficient for the sputum to dissolve and for the extraneous organisms necessarily associated with the tubercle bacilli in such cases to be killed off. The deposit was washed with saline solution, re-centrifuged, and, after this process had been repeated twice, was sown on egg medium as prepared and introduced by Dorset $\left(1902^{8}\right)$. According to Griffith $\left(1914^{11}, 1916^{12}\right)$, the washing with saline solution can be discarded, as the amount of antiformin left unreduced in such mixture is insufficient to interfere with the growth of the tubercle bacilli.

This means of obtaining primary tubercle cultures has been found useful by many workers.

Brown and Smith (19104) were successful in raising cultures by the use of antiformin from thirty-three out of thirty-five sputum cases.

Similar result was also obtained by Paterson $\left(1910^{17}\right)$, who recommends strength of 20 per cent. antiformin in the whole solution, that is, 10 c.c. of sputum plus 2.5 c.c. of antiformin, left at room temperature for twenty-four hours, or for from four to six hours at $37^{\circ} \mathrm{C}$. This author did not find that there is any apparent interference with the viability of the bacilli, as the growth occurred at the same rate as in the case of those not so treated.

Griffith $\left(1914^{11}, 1916^{12}\right)$ has employed this method extensively in raising primary cultures from sputum, and found it quite reliable and serviceable. He, however, noticed a distinct inhibitory action on the viability of the tubercle bacilli, should antiformin be left for more than a certain length of time.

Cruickshank $\left(1912^{6}\right.$ ), amongst others, found it not only useful for isolating cultures direct from sputum, but also for the detection of tubercle bacilli in a sputum which bas yielded a negative result with the ordinary smear preparation. He adrocates the use of atrength of from 15 per cent. to 20 per cent. of antiformin in the whole mixture.

The British Royal Commission (1911 ${ }^{1}$ ) in their investigation have, in part, employed this method with success in obtaining primary cultures from material other than sputum.

Antiformin, as originally introduced by Uhlenhuth and X ylander $\left(1908^{19}\right)$, is a combination of potassium hypochlorite and potassium hydrate in such proportions that 100 grms. of the mixture will liberate $5.3 \mathrm{grms}$. of chlorine gas. As now generally employed, antiformin consists of equal parts of liquor sodæ chlorinatæ (B.P.) and sodic hydrate in 15 per cent. aqueous solution.

\section{Differential Tests between " Human" and "Bovine" Types.}

The strains isolated by me, twenty-nine in all, have been tested on rabbits as to their type, and their cultural characters were also observed. On these two tests alone were the strains classified as to whether " human" or "bovine."

\section{Cultural Test.}

As an aid to distinguishing the type of tubercle bacillus by cultural characters, the routine method adopted was to inoculate the 
tuberculous material on plain as well as on glycerin egg medium, and to observe the growth at the end of the second or third week. The terms "dysgonic" and "eugonic," as employed by the British Royal Commission to denote respectively that the bacillus grows with difficulty or with readiness, appropriately express the characteristics exhibited by the "bovine" type in the former, and, in most cases, by the " human" type in the latter instance.

The human tubercle bacilli on Dorset's plain egg (Plate V. Fig. 1) grow more rapidly and luxuriantly than does the "bovine" type, the colonies, very often numerous, becoming visible to the unaided naked eye within the first ten or further days. Sometimes, however, their appearance may be delayed. When grown on glycerin egg, the difference between the growths of the two types is even more apparent, and, in addition, the "human" culture has a characteristic wrinkled appearance and a tendency in some cases to become pigmented.

In the case of the bovine tubercle bacilli (Plate V. Fig. 2), the growth does not appear before the third week; usually its appearance is even later than this. On glycerin egg the growth, if present, assumes a moist appearance, which is one of its cbaracteristic and almost constant features. Rarely do the colonies show pignentation, at all events, in the primary and in the first few generations, and, instead of having a wrinkled surface, they form a thin greyish uniform layer of growth. Often primary cultures of this type fail to develop on glycerin egg, but, after repeated subcultures and prolonged growth on this medium, and when they have become accustomed to the glycerin, their growth tends to an increasing luxuriance and ultimately may even lose many of its distinguishing features.

It becomes evident, therefore, that, while such cultural differences as exist between the two types can be observed on most of the suitable media, they become more marked when glycerin is present as one of the constituents of the medium employed.

\section{Animal Test.}

In the choice of the rabbit as a means of identification of the two types of tubercle bacillus, I was guided by the experience of previous workers.

As the outcome of an extensive series of experiments, the British Royal Commission (1911 3) came to the conclusion that "the results produced by injecting the bovine tubercle bacillus into calves and rabbits in the above doses are thus very striking and definite, and taken with the cultural characters of the bacillus afford a trustworthy means of recognising the bovine tubercle bacillus. Indeed, as our investigation progressed, we found that it was sufficient to inoculate rabbits for differential diagnosis."

$\Lambda$ gain Park and Krumwiede $\left(1910^{15}\right)$, amongst others, working on the same lines found that the rabbit is the best animal to use for testing virulence for diagnosis of the type of tubercle bacillus. 
The important fact was thus established that with the rabbit alone one is able to distinguish with certainty the "bovine "from the " human" tubercle bacillus, and that, in this respect, it serves as useful a purpose as the calf.

\section{Mode of Injection and Dosage.}

In the use of the rabbit as a means of differential diagnosis four methods of inoculation can be employed, namely, intra-articular, subcutaneous, intraperitoneal, and intravenous.

1. The intra-articular method of injection for differentiation between the "human" and "bovine" types of tubercle bacilli was introduced by Fraser $\left(1912^{\circ}\right)$. He has chosen the knee-joint of the rabbit as being the most convenient and accessible, and, in his opinion, the ideal situation is the synovial membrane in which to demonstrate such distinction. The test is judged by the degree of reaction, clinical and pathological, consequent upon inoculation into the joint with 1 c.c. of bacillary emulsion.

2. The oubcutaneous method has the disadvantage that the local lesion may ulcerate, and infective material may be discharged, leading to contamination of the surroundings.

3. The intraperitoneal injection is free from this objection, but, like the subcutaneous route, it takes longer time for the animal to show indications of the disease, and, in this respect, is not equal to the fourth method.

4. The intravenous method. The British Royal Commission (1911 s) is of the opinion that for an intravenous injection into the rabbit, for purpose of identification, a dose of $0.01 \mathrm{mgrm}$. of tubercle culture should be used. This mode of injection with this dose was, in part, also adopted by, amongst others, Park and Krumwiede $\left(1910^{16}\right)$, and Fraser $\left(1912^{10}\right)$.

I have employed, throughout the course of my investigation, the intravenous route for differentiation, giving $0.01 \mathrm{mgrm}$. of culture, previously dried over concentrated sulphuric acid, as the dose, and rabbits were utilised for reasons of economy and convenience.

Every strain of culture isolated has been subjected to this test, and its result along with the cultural characters was accepted as the basis of identification. Further, wherever a strain has been demonstrated by the first rabbit injection to be of the bovine type, this result was again corroborated by a second rabbit injection.

The weight of the rabbit before inoculation was taken and recorded, and also that at death. If possible, rabbits weighing about 1500 grms. were employed, but those of other weights have also been utilised, and my experience failed to detect any appreciable difference in the pathological findings caused by variation in size of the animals.

Reliance has been placed on the macroscopic inspection of the lesions for differentiation; but, in this respect, there is the possibility of pseudo-tuberculosis being mistaken for tuberculosis. This can, however, be easily avoided by remembering the fact that pseudotuberculosis chiefly affects the vermiform appendix, the glands, the opleen, and the liver-rarely the lung. Further, it can readily be distinguished by making films from the nodules. Each of the two

2-Jh or Patr. - vOL. XxI. 
types of tubercle bacilli produces distinct and different changes on rabbits.

(a) In the first instance, a rabbit injected intravenously with a dose of $0.01 \mathrm{mgrm}$. of tubercle bacilli of the bovine type presents the following characteristics (Plate V. Fig. 3). The animal loses weight, sometimes even to the extent of half of its initial weight, and almost invariably succumbs within six weeks after inoculation. On autopsy: the lungs are very voluminous and almost completely fill the chest. They are studded throughout with tubercles or masses of varying sizes; these are often large as the result of the confluence of smaller tubercles, forming grey caseating nodules. The spleen is enlarged, sometimes extremely so, and closely beset with caseating tubercles. The liver may be moderately enlarged, and commonly shows, scattered through its substance, numerous grejish-yellow tubercles. The kidneys often, though not invariably, become the seat of many caseating miliary tubercles. The lymphatic glands are practically always affected, more particularly those of the bronchi, and show central caseation.

(b) On the other hand, a rabbit inoculated with the same dose of the human tubercle bacilli, under identical conditions as regards weight and mode of administration, never dies of tuberculosis within three months. If death does occur within this time, it is due to causes other than tuberculosis. Instead, the animal generally lives for a long time, and, if killed at the end of three or four months, is often found in good health, and not infrequently has increased in weight. The lungs in such cases very often are collapsed, and fall away from the chest wall when this is opened. They show either no tuberculosis or, at most, a small number of scattered grey tubercles already fibrotic or calcified; some of these may occasionally develop into nodules with caseous foci in the centre. The rest of the organ is crepitant and, to all appearances, healthy. The spleen is seldom enlarged and rarely, if ever, affected. The liver also rarely shows any tubercles. The kidneys are inrolved in a large number of cases, and generally reveal in the cortex a few grey tubercles. The lymphatic glands are very seldom affected (Plate V. Fig. 4).

As the outcome of a series of inoculations into rabbits, and taking the facts already outlined into consideration together with those observed by other workers, the conclusion can safely be drawn that, by means of the rabbit tests alone, tubercle bacilli as they occur in lesions in the human body can be divided into two distinct groups. One group possesses identical cultural characters and virulence for rabbits with those exhibited by tubercle bacilli isolated from bovines, and may be thus termed the "bovine" type; the other group has a low virulence for rabbits, is practically always obtained from a human source, and may be termed the "human" type.

\section{RESULTS.}

Twenty-eight of the twenty-nine strains isolated by me from the sputum, produced, in the rabbit, either no tuberculosis or only a retrogressive tuberculosis, similar to that produced by bacilli of the "human" type.

The remaining culture showed well-marked cultural characteristics of the "bovine" type, and was of high virulence for the rabbit. A 
rabbit inoculated with this strain died during the sixth week after injection, and, on examination, showed extensive tuberculosis of a rapidly progressive type. The virulence of this culture was again tested, and the same extensive tuberculous lesions were found. The cultural characters and the pathological lesions in this case, therefore, agreed in essential particulars with that produced by the tubercle bacilli of the "bovine" type.

The appended table comprises the work on this subject done by various investigators up to the present. It is to be noted that, of the 998 cases, the bacilli from three cultures were found to be of a mixed type of both "human" and "bovine," and from four of a pure "bovine" type; of the latter cases, all occurred in this country, Edinburgh alone claiming two.

\section{Tabee of Total Cases.}

\begin{tabular}{|c|c|c|c|c|}
\hline Authors. & Totsl. & Humsn. & Borine. & Mixed. \\
\hline 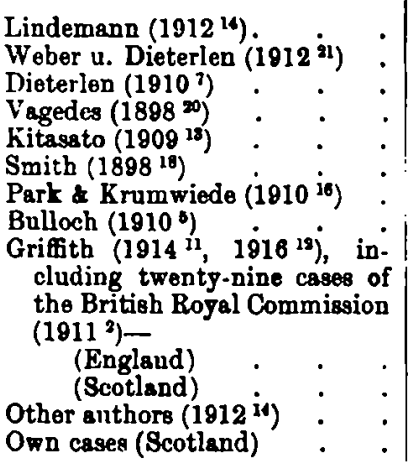 & $\begin{array}{r}41 \\
9 \\
50 \\
6 \\
152 \\
6 \\
291 \\
23\end{array}$ & $\begin{array}{r}40 \\
9 \\
50 \\
6 \\
152 \\
6 \\
291 \\
23\end{array}$ & $\begin{array}{l}- \\
\overline{-} \\
\overline{-} \\
\overline{-} \\
\overline{-} \\
-\end{array}$ & $\begin{array}{l}1 \\
- \\
- \\
- \\
- \\
- \\
-\end{array}$ \\
\hline & 998 & 991 & 4 & 3 \\
\hline $\begin{array}{l}\text { (a) Includi } \\
\text { (b) Includi } \\
\text { (c) Cass of }\end{array}$ & $\begin{array}{l}0 \text { aty } \\
\text { o aty } \\
\text { ong St }\end{array}$ & $\begin{array}{l}\text { ains. } \\
\text { ains. } \\
\text { and of }\end{array}$ & & \\
\hline
\end{tabular}

The following is an account of the seven cases from which bacilli of the pure "bovine" or the mixed "buman" and "bovine" type were isolated :-

1. De Jong Stuurman's Case (quoted from Griffith, 1914 "). - "The patient was a peasant woman, æt. 27. A glycerin serum culture from the sputum produced fatal general tuberculosis in three calves. . . . No rabbits were tested. The culture is stated to have grown luxuriantly. Only one sample of sputum was investigated."

2. Kossel's Case (quoted from Griffith, 1914"1). - "The patient was a female letter-carrier, æt. 27. Sputum for investigation was collected twise. 
. . From the first sample of sputum a culture of human type was isolated through the guinea-pig and a culture of bovine type was obtained through the rabbit. From the second sample of sputum a pure culture of human tubercle bacilli was isolated direct."

3. Iindemann's Case (quoted from Griffith, $1914{ }^{11}$ )._- "The patient was a musician, male, æt. 20. Three samples of sputum were investigated. A culture isolated from each sample through the guinea-pig grew on broth like the human tubercle bacillus. Each of the cultures produced in rabbits slight tuberculosis typical of infections with human tubercle bacilli, except that one rabbit in each series showed a tubercle or two in the kidneys. . . . The rabbit culture obtained was dysgonic and highly virulent for calves and rabbits. A virulent culture was also derived from a guinea-pig which had been inoculated with the second sample."

4. British Royal Commission Case No. 1 (investigated by Griffith, $1911^{2}$ ). -The patient, æt. 21 , was a butcher by occupation. He had pneumonia and pleurisy ten months before admission, and had suffered from cough since then. The clinical signs showed consolidation of the left lower lobe of the lung. Cultures from the first sample of sputum were identical in cultural characters and virulence for the calf, rabbit, and guinea-pig, with the bovine tubercle bacillus. Three other samples of sputum were collected at various intervals after the first. All the strains agreed with those first isolated in their cultural characters and proved highly virulent for rabbits.

5. British Royal Commission Case No. 2 (investigated by Griffith).-The patient was a male, at. 31 , a bricklayer by occupation. He had pneumonia and pleurisy before admission. A culture isolated from the sputum exhibited the cultural characters of the bovine type and was highly virulent for calves, rabbits, and guineat-pigs. The sccond specimen of sputurn collocted 118 days after the first yieldet cultures identical in cultural characters and virulence for the calf and rabbit with the culture first isolated.

6. Griffith's Case (1914 "'). - The patient was a girl, xt. 16 and 7 months, a die-stamper by occupation. She was a breast-fed child and had had no serious illness previously. She was in the habit of drinking unboiled milk until shortly before admission to the hospital. Three specimens of sputun were collected at intervals of three weeks each, and yielded cultures which possessed cultural characters and virulence for ribbits identical with those shown by the bovine tubercle bacillus.

7. Oon Case. ${ }^{1}$-The patient was a man, æt. 41, who had had a somewhat, severe attack of hæmoptysis in 1913, and, previous to this, also two attacks of pleurisy. He recovered sufficiently to take things very quietly, although he was unable to attend to work. In spite of sanatorium treatment and careful feeding, the disease, affecting both lungs, appeared to make only slow, steady progress. Dyspncea was a prominent symptom during the latter half of his illness, and this ultimately became so marked that the slightest exertion was liable to bring it on. He died suddenly as the result of a self-inflicted wound. Only one specimen of sputum (obtained in February 1914) was available for investigation.

The seven persons referred to above, in whose sputum bovine tubercle bacilli were isolated either in a pure or mixed strain, all ended fatally; in none of these cases was an autopsy performed.

The line of research was suggested to me by Professor James Ritchie; for this and for much valuable advice my most sincere thanks are due to him. I wish also to express my gratitude for the

\footnotetext{
1 For the clinical notes of this case I am indelited to Dr. Edward M. Tyrrell of Galashiels.
} 
privilege of working in the Royal College of Physicians' Laboratory, Edinburgh, and for all the facilities there granted to me. This work was done whilst I was bolding the Carnegie Research Scholarship and the McCunn Research Scholarship, and on a grant from the Moray Research Fund, for which I desire to record my indebtedness.

\section{REFERENCES.}

1. British Royal Commis- "Final Report on Tuberculosis," 1911, Part SION.

II. App. vol. i. p. 7.

2. " " $" \quad$ Ibid., pp. 8, 149, 151 .

3. " " " Ibid., Part I. pp. 5, 6.

4. Bruwn, L., AND Suith, D. Journ. Merl Research, Boston, 1910, vol. xxii. p. 517.

5. Bullook, W. . . . . "Horace Dobell Lecture," R.C.P., London, Nov. 10, 1910.

6. Cruickshank, J. . . . Brit. Med. Journ., London, 1912, vol. ii. p. 1298.

7. Dieterlen . . . . . Tub.-Arb. a. d. Kais. Ges.-Amt., Berlin, 1910, Heft 10, S. 101

8. Dorset, M. . . . . . "American Medicine," 1902, vol. iii. p. 555.

9. FraSER, J. . . . . . Brit. Med. Journ., London, 1912, vol. ii. p. 1432.

10. " . . . . . Journ. Exper. Med., Baltimore, 1912, vol. xvi. p. 432.

11. Griffite, A. S. . . . Brit. Med. Journ., London, 1914, vol. i. p. 1171.

12. " . . . . Lancet, London, 1916, vol. i. p. 721.

13. Kitasato, S. . . . . Ztzchr. f. Hyg., Leipzig, 1909, Bd. Ixiij. S. 517.

14. Lindemanv, E. A. . . . Tub.-Arb. a. d. Kais. Ges.-Amt., Berlin, 1912, Heft 12, S. 11 (Cases of, and collected by, Lindemann).

15. Park, W. H., and KRUM- Journ. Med. Research, Boston, 1910, vol. WIRDE, C. xxiii. p. 205.

16. " Ibid., p. 359.

17. Paterson, R. C. ". . . Ibid., 1910, vol. xxii. p. 315.

18. Sмith, T. . . . . . . Journ. Exper. Med., Baltimore, 1898, vol. iii. p. 451.

19. Uhlenguth v. XriandrR Berl. Klin. Wchnschr., 1908, Heft 2, Bd. xlv. 8. 1346 .

20. VAGEDES . . . . . . Zkschr. f. Hyg., Ieipzig, 1898, Bd. xxviii. S. 276.

21. Weger, A., v. Dimtralex . Tub.-Arb. a. d. Kaiz. Ges.-Amt., Berlin, 1912, Heft 12, S. 1.

\section{DESCRIPTION OF PLATE $\mathrm{v}$.}

Fic. 1.-Primary cultures of human tubercle becilli 5 woeks old.

(a and b) On glycerin ogg medium. Profuse, closely packed, rsised colonies. Note the dry appearance. ( $c$ and d) On Dorset's plain egg medium. Largo, raised colonies. Noto the dry appearance. 
F1a. 2.-Primary cultures of bovine tubercle bacilli, 5 weeks old.

$(a$ and $b$ ) On Dorset's plain egg medium. Scanty fat colonies. (Moist appesrance lost in photograph.) (c) On glycerin egg medium. Note the almost complete absence of growth. (Lines on culture due to strokes of needle.)

Fra. 3. - 1 rabbit inoculated intravenously with 0.01 mgrm. of dry bovine tubercle bacilli ; animal died on the thirty-ninth day after injection. Initial weight, 2255 grms.; final weight, 1350 grms. Note the following: The lungs are voluminous and studded throughout with miliary tubercles; some of these are confluent. The liver shows many small tubercles. The spleen is enormously enlarged and full of tubercles. The kidneys show several tubercular nodules.

Fia. 4. - A rabbit inoculated intravenously with $0.01 \mathrm{mgtm}$. of dry human tubercle bacilli ; animal killed on the ninety-fifth day after injection. Initial weight, 1070 grms. ; final weight, 1400 grms. Note the following: The lungs are collapsed and show several hard tuberculous nodules at their base, of a chronic and retrogressive character. Elsewhere the organ is not affected. The liver is free from the disease. The splcen is not enlarged and does not show the presence of any tubercles. The kidneys show several small tubercles. 


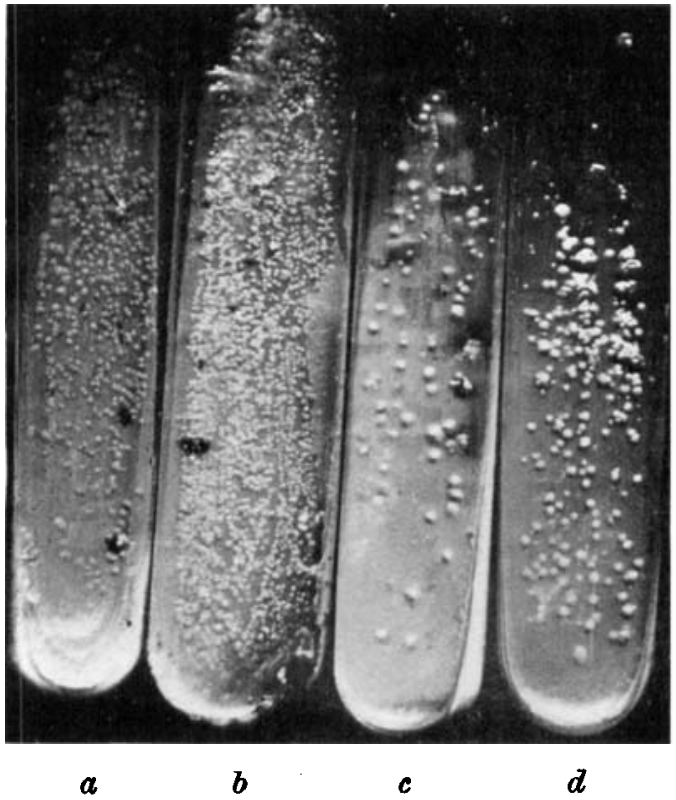

Fig. 1.

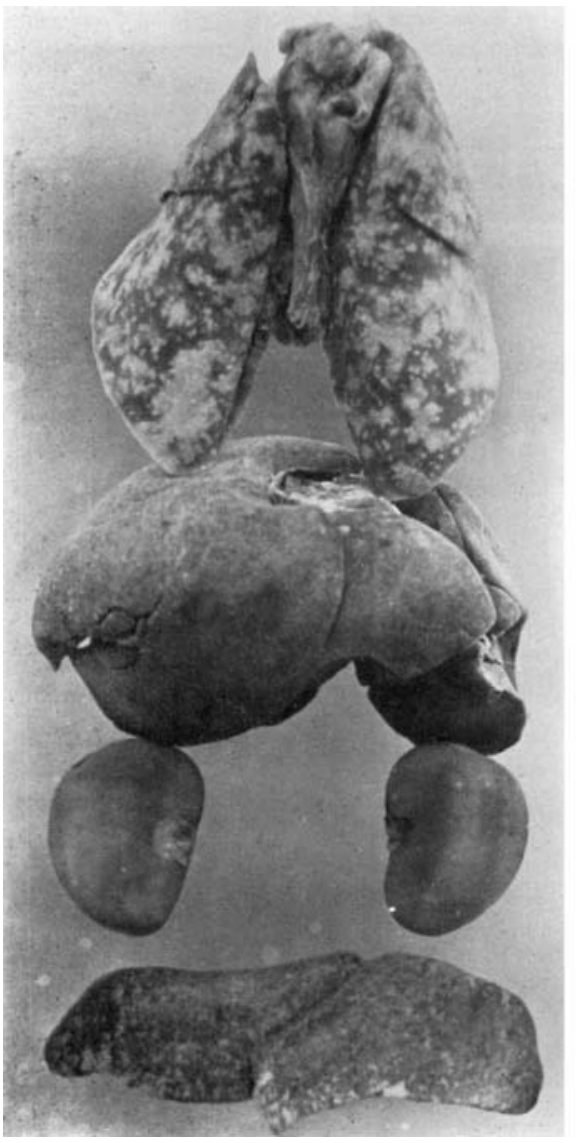

Fig. 8.
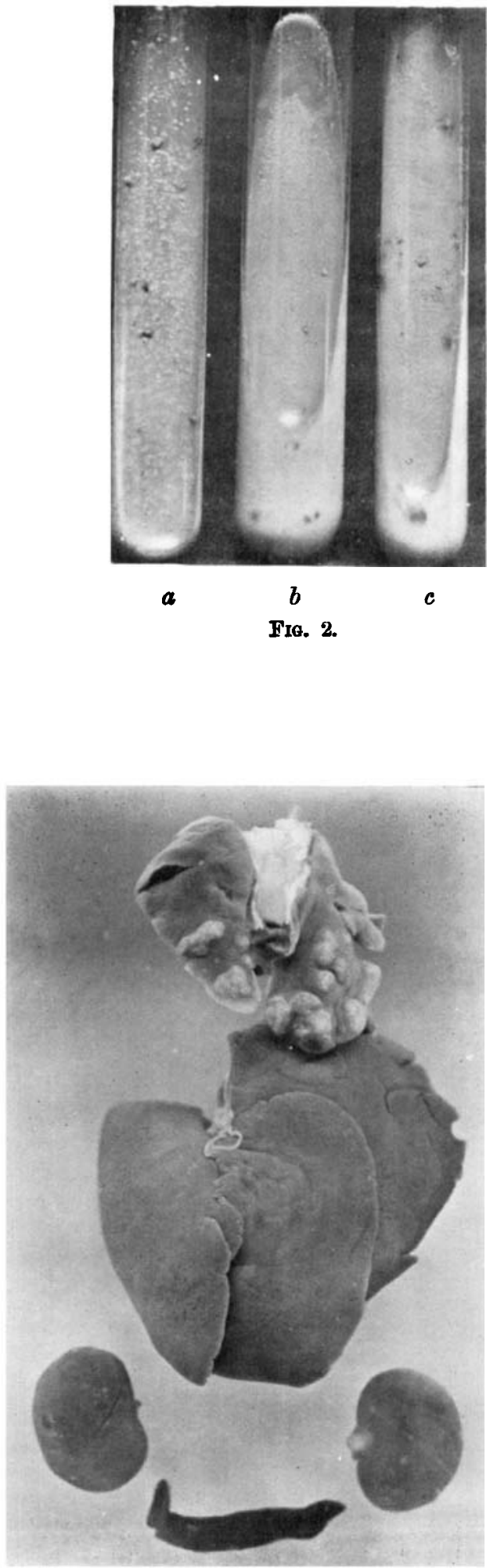

Fig. 4 